\title{
Associative Learning Elicits the Formation of Multiple-Synapse Boutons
}

\author{
Yuri Geinisman, ${ }^{1}$ Robert W. Berry, ${ }^{1}$ John F. Disterhoft, ${ }^{1}$ John M. Power, ${ }^{2}$ and Eddy A. Van der Zee ${ }^{3}$ \\ ${ }^{1}$ Department of Cell and Molecular Biology, Northwestern University Medical School, Chicago, Illinois 60611, 2Division of \\ Neuroscience, John Curtin School of Medical Research, Australian National University, Canberra ACT 2601, Australia, \\ and ${ }^{3}$ Department of Zoology, University of Groningen, 9751 NN Haren, The Netherlands
}

The formation of new synapses has been suggested to underlie learning and memory. However, previous work from this laboratory has demonstrated that hippocampus-dependent associative learning does not induce a net gain in the total number of hippocampal synapses and, hence, a net synaptogenesis. The aim of the present work was to determine whether associative learning involves a specific synaptogenesis confined to the formation of multiple-synapse boutons (MSBs) that synapse with more than one dendritic spine. We used the behavioral paradigm of trace eyeblink conditioning, which is a hippocampus-dependent form of associative learning. Conditioned rabbits were given daily 80 -trial sessions to a criterion of $80 \%$ conditioned responses in a session. During each trial, the conditioned stimulus (tone) and the unconditioned stimulus (corneal airpuff) were presented with an intervening trace interval of $500 \mathrm{msec}$. Brain tissue was taken for morphological analyses $24 \mathrm{hr}$ after the last session. Unbiased stereological methods were used for obtaining estimates of the total number of MSBs in the stratum radiatum of hippocampal subfield CA1. The results showed that the total number of MSBs was significantly increased in conditioned rabbits as compared with pseudoconditioned or unstimulated controls. This conditioning-induced change, which occurs without a net synaptogenesis, reflects a specific synaptogenesis resulting in MSB formation. Models of the latter process are proposed. The models postulate that it requires spine motility and may involve the relocation of existing spines from nonactivated boutons or the outgrowth of newly formed spines for specific synaptogenesis with single-synapse boutons activated by the conditioning stimulation.

Key words: associative learning; trace eyeblink conditioning; hippocampus; CA1 stratum radiatum; multiple-synapse boutons; synaptic plasticity; synaptogenesis; spine motility
More than a century ago, cellular mechanisms of learning and memory were postulated to include both the establishment of new synaptic connections and the restructuring of existing ones to make them more efficacious (Ramón y Cajal, 1893; Tanzi, 1893). Subsequent electron microscopic studies have indicated that both types of synaptic alteration may occur in pertinent regions of the vertebrate brain as a consequence of behavioral learning (for review, see Greenough and Bailey, 1988; Bailey and Kandel, 1993; Andersen and Soleng, 1998; Klintsova and Greenough, 1999; Geinisman, 2000). However, some studies have failed to demonstrate a learning-related increase in total synapse number on the basis of analyses of samples from the entire synaptic population of a given brain region (for review, see Geinisman, 2000). This suggests that a net synaptogenesis may not necessarily underlie the formation of memories after the learning of some behavioral tasks. It is conceivable that in such cases, learning-induced synaptogenesis may be confined to rearranging only a specific subset of synaptic connections to establish a memory trace.

A specific synaptogenesis of this kind may involve the formation of multiple-synapse boutons (MSBs). Such boutons form separate synapses with two or more postsynaptic elements instead of only one synapse with a single postsynaptic element, as is the

Received March 22, 2001; revised April 25, 2001; accepted May 18, 2001.

This work was supported by National Institutes of Health Grants NS34582 and AG17139 (Y.G.), and AG08796 (J.F.D.).

Correspondence should be addressed to Yuri Geinisman, Department of Cell and Molecular Biology, Northwestern University Medical School, 303 East Chicago Avenue, Chicago, IL 60611. E-mail: yurig@northwestern.edu.

Copyright (C) 2001 Society for Neuroscience 0270-6474/01/215568-06\$15.00/0 case for single-synapse boutons. The results of earlier studies indicate that the incidence of MSBs is increased in rat cerebellar and motor cortices after acquisition of complex motor skills (Federmeier et al., 1994; Jones et al., 1999) and in the visual cortex of rats housed in a complex environment (Jones et al., 1997). It has also been demonstrated (Toni et al., 1999) that the proportion of MSBs is increased after the induction of hippocampal long-term potentiation (LTP), which is widely regarded as a synaptic model of memory (Bliss and Collingridge, 1993).

In light of these observations, we decided to explore the possibility that hippocampus-dependent associative learning, which does not alter the total number of synapses in the CA1 stratum radiatum (Geinisman et al., 2000) and, hence, does not involve a net synaptogenesis, nevertheless induces a specific synaptogenesis leading to the formation of MSBs. For this purpose, we reexamined electron micrographs obtained in our previous study (Geinisman et al., 2000). In that study, the behavioral paradigm of trace eyeblink conditioning was used. Lesions of the hippocampus have been shown to prevent acquisition of the trace eyeblink conditioned response in rabbits (Solomon et al., 1986; Moyer et al., 1990; Kim et al., 1995). Moreover, electrophysiological recordings made from rabbit hippocampal slices have revealed that trace eyeblink conditioning is accompanied by increases in the synaptic responsiveness (Power et al., 1997; Geinisman et al., 2000) and postsynaptic excitability (Disterhoft et al., 1986; Moyer et al., 1996) of CA1 pyramidal neurons. Therefore, in the present study we determined whether additional MSBs are formed in the CA1 stratum radiatum of those rabbits that acquired the trace 
eyeblink conditioned response. We provide evidence for a conditioning-induced increase in the total number of MSBs in the synaptic layer examined.

\section{MATERIALS AND METHODS}

Experimental animals and behavioral training. Female New Zealand albino rabbits (Oryctolagus cuniculus) of 8-10 weeks of age were purchased from Hazelton Rabbitry (Denver, PA). All procedures related to the care and treatment of animals were approved by the Animal Care and Use Committee of Northwestern University and performed in accordance with the guidelines of the National Institutes of Health. Rabbits were trained in pairs in individual sound-attenuated chambers and received either trace eyeblink conditioning or, as a control, pseudoconditioning according to an established experimental protocol (Thompson et al., 1996; Moyer et al., 2000). Conditioned rabbits were given daily training sessions, each consisting of 80 trials with a randomly determined intertrial interval between 30 and $60 \mathrm{sec}$, which was adjusted to give a mean of $45 \mathrm{sec}$. During each trial, the conditioned stimulus (CS; $100 \mathrm{msec}, 85$ $\mathrm{dB}, 6 \mathrm{kHz}$ tone) not only preceded the unconditioned stimulus (US; 150 msec, 3.0 psi corneal airpuff) but was also separated from it by a stimulus-free, or "trace," interval of $500 \mathrm{msec}$. An eyeblink response was considered to be conditioned if it occurred after CS onset and before US onset. Conditioned animals were trained until they reached a learning criterion of $80 \%$ conditioned responses during a training session. A total of 5-10 sessions were required to reach criterion. Pseudoconditioned rabbits received explicitly unpaired presentations of the same CS and US that were used in conditioning. Each daily session of pseudoconditioning consisted of $80 \mathrm{CS}$-alone and 80 US-alone trials. Both the CS and the US were administered in pseudorandom order at a variable intertrial interval that averaged $22.5 \mathrm{sec}$. The timing of each stimulus was determined independently to ensure the same probability of the CS preceding the US and of the US preceding the CS. Pseudoconditioned rabbits were sessionmatched with their conditioned counterparts to control for nonspecific effects such as sensitization. The animals were coded and transcardially perfused for microscopy $24 \mathrm{hr}$ after the last training session.

Tissue preparation. The protocols for perfusion fixation and tissue processing, as well as for unbiased stereological sampling and counting, have been described in detail earlier (Geinisman et al., 1996, 2000), and only a brief account of these procedures is given below. Animals were deeply anesthetized with a combination of xylazine $(6 \mathrm{mg} / \mathrm{kg}$, i.m. $)$ and ketamine hydrochloride ( $45 \mathrm{mg} / \mathrm{kg}$, i.m.), followed $15 \mathrm{~min}$ later by pentobarbital sodium $(75 \mathrm{mg} / \mathrm{kg}$, i.m. $)$. They were then transcardially perfused with the following consecutively administered solutions: PBS containing heparin sodium $(10 \mathrm{U} / \mathrm{ml})$, an aldehyde fixative $(1 \%$ paraformaldehyde, $1.25 \%$ glutaraldehyde, and $0.02 \mathrm{mM} \mathrm{CaCl}_{2}$ in $0.12 \mathrm{M}$ phosphate buffer, $\mathrm{pH} 7.3$ ), and the same fixative at twice the aldehyde concentration. The left hippocampal formation was dissected free and physically straightened to diminish its natural curvature, which produced no apparent mechanical damage to the fixed tissue and did not cause alterations in the ultrastructure of tissue components as compared with tissue treated without this manipulation. The straightened hippocampal formation was cut, perpendicular to its septotemporal axis, into 11-14 consecutive slabs, each $1.5 \mathrm{~mm}$ thick. The position of the first cut within the first $1.5 \mathrm{~mm}$ interval from the septal pole was selected randomly, and the subsequent cuts were placed at a uniform interval from each other. The slabs were treated with $\mathrm{OsO}_{4}$, dehydrated in ethanol solutions of increasing concentrations, and flat-embedded in Araldite.

Estimation of the total volume of the CA1 stratum radiatum. This procedure was performed at the light microscopic level according to the Cavalieri principle. The thickness of embedded slabs was measured in an inverted microscope at a final magnification of $18 \times$. Then, $3-\mu \mathrm{m}$-thick sections were prepared from the septal face of tissue slabs, stained with Azur II-methylene blue, and used to estimate the area of sectional profiles of the CA1 stratum radiatum by point counting. The volume of CA1 stratum radiatum was calculated as the product of the sum of profile areas and the mean thickness of embedded slabs.

Stereological sampling and counting of MSBs. In each animal, MSBs were sampled in six fields that were positioned randomly along the septotemporal axis and in a systematic random manner along the other two (CA2-subicular and cell body-apical dendrite) axes of the CA1 stratum radiatum. A total of 31-38 consecutive ultrathin sections were prepared from each sampling field and used to obtain electron micrographs (final magnification, $20,000 \times$ ). Each micrograph series was assigned a code number to be decoded after completion of all analyses.
Initially, MSBs were identified on micrographs of serial sections as single axonal swellings that contained synaptic vesicles and formed synapses with two or more dendritic spines. An apposition between an MSB and a spine was classified as a synapse if the spine exhibited a postsynaptic density. Then MSBs were counted with disectors. Each disector consisted of electron micrographs of two adjacent serial sections. The mean area of the disector counting frame was $80.0 \mu \mathrm{m}^{2}$. The mean disector height, i.e., the thickness of a reference section, was $0.080 \mu \mathrm{m}$, as estimated with Small's technique of minimal folds (Royet, 1991). Thus, the mean disector volume was equal to $6.40 \mu \mathrm{m}^{3}$. From each section series, 15 consecutive sections were selected with a random start from section 3,4 , or 5 and used as reference sections of disectors. The last 12-20 sections of each series were not used as reference sections to ensure that all counted MSBs were included in their entirety in the section series. Sections immediately preceding the reference ones were used as look-up sections of disectors. An MSB was counted if its profile was seen on a reference section micrograph but was not observed on a look-up section micrograph. A sample of 32-53 MSBs (mean =45) was obtained from each animal.

Estimation of the numerical density and the total number of MSBs in the $C A 1$ stratum radiatum. The numerical density of MSBs per unit volume was calculated as their mean number counted per disector divided by the mean disector volume. The parameter of total MSB number was calculated as the product of CA1 stratum radiatum volume and the numerical density of MSBs.

\section{RESULTS}

\section{Total MSB number is increased in the CA1 stratum radiatum of conditioned rabbits relative to pseudoconditioned controls}

Examination of electron micrographs of the rabbit CA1 stratum radiatum revealed that some presynaptic boutons made synapses with two or more postsynaptic elements. A typical MSB in this layer is a single presynaptic bouton that forms separate synapses with two spine heads (Fig. 1). Such MSBs can be unequivocally identified only in serial sections because in single sections they usually exhibit synapses with one spine (Fig. $1 A, C$ ) and less frequently with two spines (Fig. $1 B$ ). MSBs synapsing with a dendritic shaft and a spine were encountered extremely rarely because axodendritic synapses constitute only $\sim 2 \%$ of the entire synaptic population of the CA1 stratum radiatum (Geinisman et al., 2000). Therefore, only those MSBs that formed synapses exclusively with spines were quantified. The results showed that the total number of MSBs was increased by $18.1 \%$ in the group of conditioned rabbits as compared with the pseudoconditioned group (Table 1 ) and that this change was statistically significant $\left[p_{(\alpha=0.05)}=0.0195\right.$, two-tailed randomization test for matched pairs (Siegel, 1956)].

\section{Total MSB number is increased in the CA1 stratum radiatum of conditioned rabbits relative to untrained controls}

The difference in MSB number between the two groups of animals might be attributable to an increase in the conditioned rabbits or to a decrease in the pseudoconditioned ones. To clarify this issue, a separate group of five untrained control rabbits was examined. The estimates of the total MSB number obtained from individual untrained animals $(1135,1102,1223,923$, and $1002 \times$ $10^{6}$ ) were comparable with those obtained from the pseudoconditioned controls (Table 1). Kruskal-Wallis one-way ANOVA by ranks (Siegel, 1956; Winer et al., 1991) on the differences among the three groups showed that they were statistically significant $\left[\mathrm{H}_{\text {(df }}=8.992, p=0.0112\right]$. After the overall Kruskal-Wallis test, comparisons between various groups that were taken two at a time were made with the Mann-Whitney $U$ test (Winer et al., 1991). These comparisons revealed that the conditioned rabbits had significantly more MSBs as compared with either untrained 

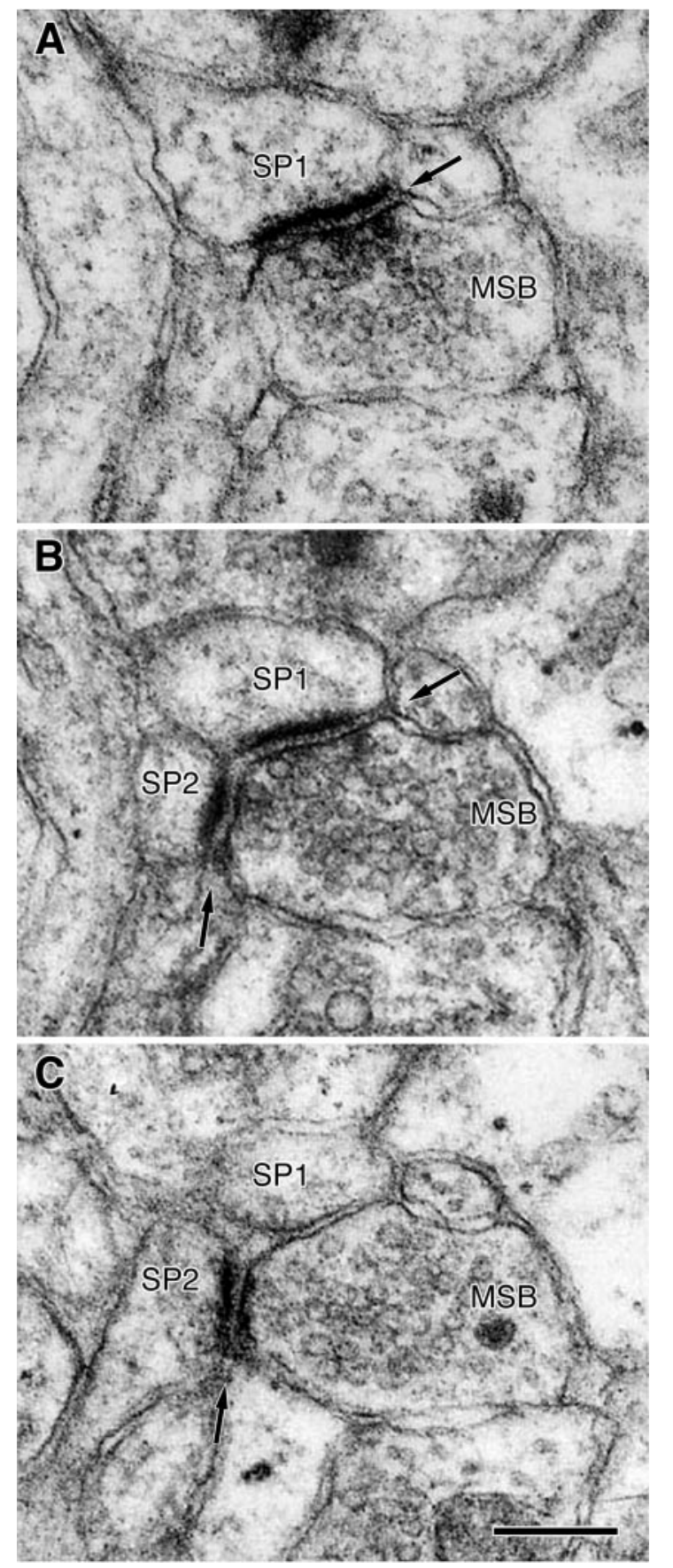

Figure 1. $A-C$, Electron micrographs of consecutive ultrathin sections demonstrating a multiple-synapse bouton $(M S B)$ that makes synapses (arrows) with two dendritic spines (SP1 and SP2). Scale bar, $0.2 \mu \mathrm{m}$.

$(\mathrm{U}=6.00, \mathrm{Z}=-2.20, p=0.0278)$ or pseudoconditioned $(\mathrm{U}=$ $10.00, \mathrm{Z}=-2.69, p=0.00708)$ controls. On the other hand, the two control groups did not differ significantly from each other with respect to total MSB number $(\mathrm{U}=17.00, \mathrm{Z}=-0.733, p=$ $0.463)$. Accordingly, the mean values $( \pm$ SEM) of this parameter estimated for the groups of untrained and pseudoconditioned rabbits $\left(1077 \pm 52\right.$ and $1047 \pm 28 \times 10^{6}$, respectively) differed by only $2.8 \%$. These data indicate that the observed difference between conditioned and pseudoconditioned animals does reflect a conditioning-induced increase in the total number of MSBs.
Table 1. Total number of MSBs $\left(\times \mathbf{1 0}^{6}\right)$ in the CA1 stratum radiatum of pseudoconditioned (PC) and conditioned (CD) rabbits

\begin{tabular}{lccc}
$\begin{array}{l}\text { Pair of } \\
\text { animals }\end{array}$ & PC rabbits & CD rabbits & $\Delta$ CD-PC \\
\hline 1 & 1232 & 1250 & 18 \\
2 & 963 & 1160 & 197 \\
3 & 1063 & 1353 & 290 \\
4 & 1085 & 967 & -118 \\
5 & 988 & 1273 & 285 \\
6 & 980 & 1364 & 384 \\
7 & 978 & 1371 & 393 \\
8 & 1056 & 1240 & 184 \\
9 & 1077 & 1147 & 70 \\
Mean & 1047 & 1236 & \\
SEM & \pm 28 & \pm 43 & \\
\hline
\end{tabular}

\section{Synapse number per MSB is not affected by trace eyeblink conditioning}

Although MSBs in the rabbit CA1 stratum radiatum usually form synapses with two spines, some MSBs synapse with three spines, and on two occasions four postsynaptic spines were seen in contact with a single MSB. We addressed the question of whether trace eyeblink conditioning changes the number of axospinous synapses per MSB. Comparison of pseudoconditioned and conditioned rabbits showed that the mean numbers $( \pm$ SEM) of axospinous synapses per MSB were the same for the two groups of animals $(2.05 \pm 0.01$ and $2.05 \pm 0.02$, respectively).

\section{Trace eyeblink conditioning does not change the number of perforated axospinous synapses per MSB}

Axospinous synaptic contacts established by MSBs include perforated synapses, which exhibit a discontinuous profile of the postsynaptic density in at least one serial section, and nonperforated synapses that show a continuous postsynaptic density profile in all consecutive sections. The perforated subtype has been implicated in synaptic plasticity that is associated with behavioral learning and hippocampal LTP (for review, see Jones and Harris, 1995; Geinisman, 2000). We estimated the number of perforated synapses per MSB and found that the groups of pseudoconditioned and conditioned animals did not differ significantly on this measure [group means \pm SEM were $0.375 \pm 0.036$ and $0.339 \pm$ 0.035 , respectively; $p_{(\alpha=0.05)}=0.426$, two-tailed randomization test for matched pairs].

\section{DISCUSSION}

\section{Associative learning involves a specific} synaptogenesis that results in the formation of MSBs

The major finding of this study is that trace eyeblink conditioning is accompanied by an increase in the total number of MSBs in the CA1 stratum radiatum. For MSBs to be formed, some axonal boutons and dendritic spines must make new synaptic contacts with each other. Therefore, the data presented here are consistent with the idea that hippocampus-dependent associative learning induces a specific synaptogenesis resulting in the formation of MSBs. It appears that this specific synaptogenesis, rather than a net synaptogenesis, supports successful learning of the trace eyeblink conditioned response because the conditioning does not increase the total number of synapses in the CA1 stratum radiatum (Geinisman et al., 2000). 


\section{MSB formation emerges as a general form of structural synaptic plasticity}

The results of the present work are in accord with those of earlier studies showing that the addition of MSBs is associated with motor skill learning (Federmeier et al., 1994; Jones et al., 1999). These findings, taken together, indicate that various forms of learning may promote MSB formation. Interestingly, this morphological alteration is not unique to behavioral learning and related phenomena such as hippocampal LTP (Toni et al., 1999) and an exposure to enriched environments (Jones et al., 1997). The incidence of MSBs has been reported to increase in various regions of the CNS under conditions that induce plasticity: in the rat dentate gyrus for boutons of the crossed temporodentate pathway after lesions of the ipsilateral entorhinal cortex (Steward et al., 1988); in the rat hypothalamus as a consequence of lactation, dehydration, or partial deafferentation (for review, see Hatton, 1990); in the cat visual cortex after monocular visual deprivation in the case of boutons on geniculocortical axons that were driven from the nondeprived eye (Friedlander et al., 1991); in the CA1 stratum radiatum of adult female rats after estradiol treatment (Woolley et al., 1996); in the rat phrenic nucleus as a result of an ipsilateral C2 spinal cord hemisection (Tai et al., 1997) or a cold block of ipsilateral bulbospinal respiratory afferents (CastroMoure and Goshgarian, 1997); in the rat motor cortex after lesions of the contralateral sensorimotor cortex (Jones, 1999); in the rat CA1 stratum radiatum after maintenance of living hippocampal slices in vitro (Kirov et al., 1999); and in the rat striatum after an ablation of the ipsilateral frontal cortex (Meshul et al., 2000). These observations indicate that the formation of MSBs may represent a general form of structural synaptic plasticity. The data of the present study are consistent with this notion because they demonstrate that the phenomenon of MSB formation is also characteristic of associative learning.

\section{Functional implications of the formation of MSBs induced by associative learning}

The structural reorganization of synaptic connectivity that is described here may have different functional implications, depending on the origin of the postsynaptic spines contacting the newly formed MSBs (Harris, 1995; Woolley et al., 1996; Jones et al., 1997). It has been documented with the aid of threedimensional reconstruction from serial ultrathin sections that individual MSBs in the CA1 stratum radiatum can synapse with spines arising from the same or different dendrites (Sorra and Harris, 1993). However, an LTP-induced increase in the proportion of activated boutons synapsing with two or more spines is essentially caused by the formation of those MSBs that synapse with spines originating from the same dendrite (Toni et al., 1999). In this study, we were unable to reliably trace many multiple spines to their dendritic origins and to obtain representative samples for quantitative analyses. It is not known, therefore, whether the MSBs that are newly formed after trace eyeblink conditioning make synapses with spines arising from the same dendrite. If this is the case, the strength of the conditioned synaptic input to target CA1 neurons may be amplified. If, however, the multiple postsynaptic spines synapsing with additional MSBs emanate from dendrites of different neighboring neurons, this may contribute to a synchronous activation of the latter and thus to the assembly of functional multineuronal units tuned to the synaptic input activated by conditioning stimulation. In either case, the effect of conditioning stimulation would be facilitated, as it would be by the learning-induced enlargement of nonperfo-
A

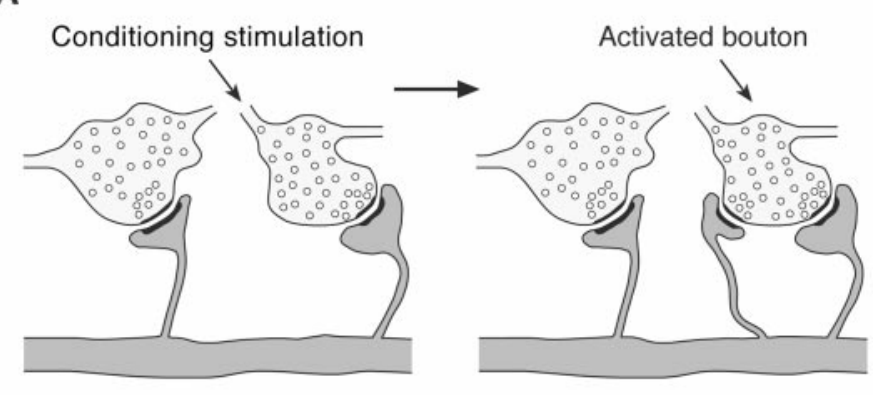

B

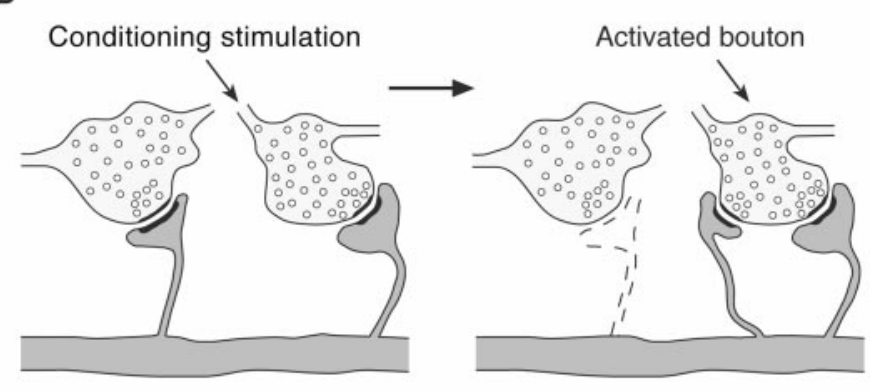

C

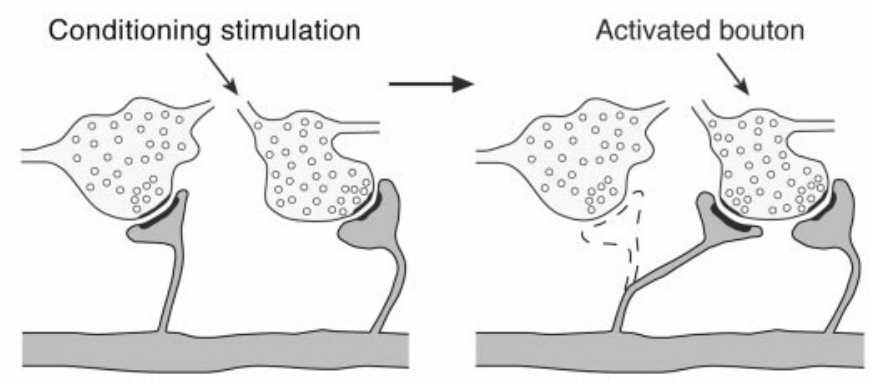

Figure 2. Models of structural plasticity underlying the formation of multiple-synapse boutons after trace eyeblink conditioning. $A$, Outgrowth of newly emerging spines for specific synaptogenesis with single-synapse boutons activated by conditioning stimulation. $B$, Coupling of the latter process with the resorption of existing spines postsynaptic to nonactivated boutons. $C$, Relocation of existing spines from nonactivated boutons for specific synaptogenesis with activated single-synapse boutons.

rated postsynaptic densities that presumably reflects an addition of AMPA receptors (Geinisman et al., 2000). It appears, therefore, that the conditioning may shape synaptic drive via both MSB formation and postsynaptic density remodeling.

\section{Models of structural plasticity underlying the formation of MSBs after trace eyeblink conditioning}

The addition of MSBs after hippocampus-dependent associative learning may reflect the establishment of synaptic contacts between either newly formed or existing presynaptic and postsynaptic elements. This suggests three models of structural plasticity that may underlie MSB formation after trace eyeblink conditioning (Fig. 2). For the purpose of simplicity, the following assumptions were incorporated into each model: (1) existing singlesynapse boutons are transformed into MSBs by the conditioning, and (2) the spines that are postsynaptic to newly formed MSBs originate from the same dendrite. The essence of the models, however, is not affected by either assumption. 
According to the first model (Fig. 2A), conditioning stimulation may induce the emergence of new spines and their outgrowth for a specific synaptogenesis with activated single-synapse boutons, probably in response to a signal emitted by the boutons. This model is supported by the data that were obtained by labeling live CA1 pyramidal neurons in cultured hippocampal slices with vital fluorescent markers and time-lapse two-photon imaging of their spines (Engert and Bonhoeffer, 1999; Maletic-Savatic et al., 1999). These experiments demonstrated that spines and their structural precursors, termed "dendritic filopodia," are constantly formed as well as resorbed under normal conditions and that the process of new spine formation is markedly augmented by local highfrequency stimulation of dendrites that elicits LTP.

The second model (Fig. $2 B$ ) takes into account the observation made in our previous study (Geinisman et al., 2000) that the total number of axospinous synapses in the CA1 stratum radiatum is not altered by trace eyeblink conditioning (group means \pm SEM for pseudoconditioned and conditioned rabbits were $22,851 \pm 843$ and $22,809 \pm 911$ synapses $\times 10^{6}$, respectively). On the basis of the data of the present work, it can be estimated that the observed conditioning-induced increase in total MSB number results on the average in the addition of $388 \times 10^{6}$ axospinous synapses that were formed by MSBs in each conditioned animal. This would increase the mean total number of axospinous synapses in the conditioned group by $1.7 \%$ as compared with the pseudoconditioned group. Although such a trend may be too small to be detected, it is also possible that the total number of axospinous synaptic contacts actually remains constant in the conditioned animals. In accordance with the latter possibility, the second model postulates that the establishment of synaptic contacts between newly formed spines and single-synapse boutons activated by conditioning stimulation is accompanied by the resorption of some postsynaptic spines contacting nonactivated boutons (Fig. $2 B$ ). In this case, some single-synapse boutons would not form synaptic contacts. Such boutons without synapses are indeed encountered in the CA1 stratum radiatum (Shepherd and Harris, 1998; our unpublished observations),

Another model (Fig. 2C), which would not involve a change in total synapse number, stems from the discovery of protrusive spine motility (for review, see Halpain, 2000; Matus, 2000; Segal and Andersen, 2000; Wong and Wong, 2000). A remarkable ability of spines to rapidly elongate or retract in cultured hippocampal slices is especially prominent during early postnatal development, but it is retained to a certain degree after the maturation of CA1 pyramidal neurons in slices obtained from developing animals and maintained in culture (Dailey and Smith, 1996; Dunaevsky et al., 1999). Accordingly, the third model posits that, after trace eyeblink conditioning, some postsynaptic spines contacting nonactivated boutons leave their presynaptic partners, relocate to boutons activated by conditioning stimulation, and synapse with them (Fig. 2C).

Further studies are necessary to ascertain which of the three models corresponds to reality. In any event, the data reported here provide evidence that trace eyeblink conditioning promotes the formation of MSBs. This process does not require a net synaptogenesis to take place; rather, it reflects a specific synaptogenesis leading to an increase in MSB number. The latter change translates into only a small $(1.7 \%)$ increase in the total number of all synapses in the CA1 stratum radiatum, namely into an addition of $388 \times 10^{6}$ axospinous synapses to total synapse number, which was estimated to be $23,267 \times 10^{6}$ in pseudoconditioned rabbits (Geinisman et al., 2000). However, activation of no more than $3-5 \%$ of all synapses in the CA1 stratum radiatum can evoke discharge from virtually all CA1 pyramidal neurons (Andersen et al., 1980). The structural alteration reported here is, therefore, of a magnitude that appears to be sufficient for exerting a measurable facilitating effect on the synaptic responsiveness of CA1 pyramidal cells to conditioning stimulation. This would explain why a specific synaptogenesis resulting in the formation of MSBs could underlie the acquisition of the trace eyeblink conditioned response.

\section{REFERENCES}

Andersen P, Soleng AF (1998) Long-term potentiation and spatial training are both associated with the generation of new excitatory synapses. Brain Res Rev 26:353-359.

Andersen P, Silfvenius H, Sundberg SH, Sveen O (1980) A comparison of distal and proximal dendritic synapses on CA1 pyramids in hippocampal slices in vitro. J Physiol (Lond) 307:273-299.

Bailey CH, Kandel ER (1993) Structural changes accompanying memory storage. Annu Rev Physiol 55:397-426.

Bliss TVP, Collingridge GL (1993) A synaptic model of memory: longterm potentiation in the hippocampus. Nature 361:31-39.

CastroMoure F, Goshgarian HG (1997) Morphological plasticity induced in the phrenic nucleus following cervical cold block of descending respiratory drive. Exp Neurol 147:299-310.

Dailey ME, Smith SJ (1996) The dynamics of dendritic structure in developing hippocampal slices. J Neurosci 16:2983-2994.

Disterhoft JF, Coulter DA, Alkon DL (1986) Conditioning-specific membrane changes of rabbit hippocampal neurons measured in vitro. Proc Natl Acad Sci USA 83:2733-2737.

Dunaevsky A, Tashiro A, Majewska A, Mason C, Yuste R (1999) Developmental regulation of spine motility in the mammalian central nervous system. Proc Natl Acad Sci USA 96:13438-13443.

Engert F, Bonhoeffer T (1999) Dendritic spine changes associated with long-term synaptic plasticity. Nature 399:66-70.

Federmeier K, Kleim IA, Anderson BJ, Greenough WT (1994) Formation of double synapses in the cerebellar cortex of the rat following motor learning. Soc Neurosci Abstr 20:1435.

Friedlander MJ, Martin KAC, Wassenhove-McCarthy D (1991) Effects of monocular visual deprivation on geniculocortical innervation of area 18 in cat. J Neurosci 11:3268-3288.

Geinisman Y (2000) Structural synaptic modifications associated with hippocampal LTP and behavioral learning. Cereb Cortex 10:952-962.

Geinisman Y, Gundersen HJG, Van der Zee E, West MJ (1996) Unbiased stereological estimation of the total number of synapses in a brain region. J Neurocytol 25:805-819.

Geinisman Y, Disterhoft JF, Gundersen HJG, McEchron MD, Persina IS, Power JM, Van der Zee EA, West MJ (2000) Remodeling of hippocampal synapses following hippocampus-dependent associative learning. J Comp Neurol 417:49-59.

Greenough WT, Bailey CH (1988) The anatomy of a memory: convergence of results across a diversity of tests. Trends Neurosci 11:142-147.

Halpain S (2000) Actin and the agile spine: how and why dendritic spines dance? Trends Neurosci 23:141-146.

Harris KM (1995) How multiple-synapse boutons could preserve input specificity during an interneuronal spread of LTP. Trends Neurosci 18:365-369

Hatton GI (1990) Emerging concepts of structure-function dynamics in adult brain: the hypothalamo-neurohypophysial system. Prog Neurobiol 34:437-504.

Jones DG, Harris RJ (1995) An analysis of contemporary morphological concepts of synaptic remodeling in the CNS: perforated synapses revisited. Rev Neurosci 6:177-219.

Jones TA (1999) Multiple synapse formation in the motor cortex opposite unilateral sensorimotor cortex lesions in adult rats. J Comp Neurol 414:57-66.

Jones TA, Klintsova AY, Kilman VL, Sirevaag AM, Greenough WT (1997) Induction of multiple synapses by experience in the visual cortex of adult rats. Neurobiol Learn Mem 68:13-20.

Jones TA, Chu CJ, Grande LA, Gregory AD (1999) Motor skills training enhances lesion-induced structural plasticity in the motor cortex of adult rats. J Neurosci 19:10153-10163.

Kim JJ, Clark RE, Thompson RF (1995) Hippocampectomy impairs the memory of recently, but not remotely, acquired trace eyeblink conditioned responses. Behav Neurosci 109:195-203.

Kirov SA, Sorra KE, Harris KM (1999) Slices have more synapses than perfusion-fixed hippocampus from both young and mature rats. J Neurosci 19:2876-2886.

Klintsova AY, Greenough WT (1999) Synaptic plasticity in cortical systems. Curr Opin Neurobiol 9:203-208.

Maletic-Savatic M, Malinov R, Svoboda K (1999) Rapid dendritic mor- 
phogenesis in CA1 hippocampal dendrites induced by synaptic activity. Science 283:1923-1927.

Matus A (2000) Actin-based plasticity in dendritic spines. Science 290:754-758.

Meshul CK, Cogen JP, Cheng HW, Moore C, Krentz L, McNeill TH (2000) Alterations in rat striatal glutamate synapses following a lesion of the cortico- and/or nigrostriatal pathway. Exp Neurol 165:191-206.

Moyer Jr JR, Deyo RA, Disterhoft JF (1990) Hippocampectomy disrupts trace eye-blink conditioning in rabbits. Behav Neurosci 104:243-252.

Moyer Jr JR, Thompson LT, Disterhoft JF (1996) Trace eyeblink conditioning increases CA1 excitability in a transient and learning-specific manner. J Neurosci 16:5536-5546.

Moyer Jr JR, Power JM, Thompson LT, Disterhoft JF (2000) Increased excitability of aged rabbit CA1 neurons after trace eyeblink conditioning. J Neurosci 20:5476-5482.

Power JM, Thompson LT, Moyer Jr JR, Disterhoft JF (1997) Enhanced synaptic transmission in CA1 hippocampus after eyeblink conditioning. J Neurophysiol 78:1184-1187.

Ramón y Cajal S (1893) Neue Darstellung vom histologischen Bau des Centralnerevensystem. Arch Anat Physiol 319-428.

Royet J-P (1991) Stereology: a method for analyzing images. Prog Neurobiol 37:433-474.

Segal M, Andersen P (2000) Dendritic spines shaped by synaptic activity. Curr Opin Neurobiol 10:582-586.

Shepherd GMG, Harris KM (1998) Three-dimensional structure and composition of CA3 $\rightarrow$ CA1 axons in rat hippocampal slices: implications for presynaptic connectivity and compartmentalization. J Neurosci $18: 8300-8310$.

Siegel S (1956) Nonparametric statistics for the behavioral sciences, pp 184-193. New York: McGraw-Hill.
Solomon PR, Van der Schaaf EV, Thompson RF, Weisz DJ (1986) Hippocampus and trace conditioning of the rabbit's classically conditioned nictitating membrane response. Behav Neurosci 100:729-744.

Sorra KE, Harris KM (1993) Occurrence and three-dimensional structure of multiple synapses between individual radiatum axons and their target pyramidal cells in hippocampal area CA1. J Neurosci 13:3736-3748.

Steward O, Vinsant SL, Davis L (1988) The process of reinnervation in the dentate gyrus of adult rats: an ultrastructural study of changes in presynaptic terminals as a result of sprouting. J Comp Neurol 267:203-210.

Tai Q, Palazzolo KL, Goshgarian HG (1997) Synaptic plasticity of 5-hydroxytryptamine-immunoreactive terminals in the phrenic nucleus following spinal cord injury: a quantitative electron microscopic analysis. J Comp Neurol 386:613-624.

Tanzi E (1893) I fatti i le induzione nell'odierna istologia del sistema nervoso. Riv Sperim Freniatr Med Leg 19:419-472.

Thompson LT, Moyer Jr JR, Disterhoft JF (1996) Transient changes in excitability of rabbit CA1 neurons with a time course appropriate to support memory consolidation. J Neurophysiol 76:1836-1849.

Toni N, Buchs P-A, Nikonenko I, Bron CR, Muller D (1999) LTP promotes formation of multiple spine synapses between a single axon terminal and a dendrite. Nature 402:421-425.

Winer BJ, Brown DR, Michels KM (1991) Statistical principles in experimental design, pp 1028-1030. New York: McGraw-Hill.

Wong WT, Wong ROL (2000) Rapid dendritic movements during synapse formation and rearrangement. Curr Opin Neurobiol 10:188-124.

Woolley CS, Wenzel HJ, Schwartzkroin PA (1996) Estradiol increases the frequency of multiple synapse boutons in the hippocampal CA1 region of the adult female rats. J Comp Neurol 373:108-117. 